\title{
Contemporary pollen and seed dispersal in a Prunus mahaleb population: patterns in distance and direction
}

\author{
C. GARCÍA, P. JORDANO and J. A. GODOY \\ Integrative Ecology Group, Estación Biológica de Doñana, CSIC, Pabellón del Perú, Avda. María Luisa, s/n, E-41013 Sevilla, Spain
}

\begin{abstract}
Pollination and seed dispersal determine the spatial pattern of gene flow in plant populations and, for those species relying on pollinators and frugivores as dispersal vectors, animal activity plays a key role in determining this spatial pattern. For these plant species, reported dispersal patterns are dominated by short-distance movements with a significant amount of immigration. However, the contribution of seed and pollen to the overall contemporary gene immigration is still poorly documented for most plant populations. In this study we investigated pollination and seed dispersal at two spatial scales in a local population of Prunus mahaleb (L.), a species pollinated by insects and dispersed by frugivorous vertebrates. First, we dissected the relative contribution of pollen and seed dispersal to gene immigration from other parts of the metapopulation. We found high levels of gene immigration (18.50\%), due to frequent long distance seed dispersal events. Second, we assessed the distance and directionality for pollen and seed dispersal events within the local population. Pollen and seed movement patterns were non-random, with skewed distance distributions: pollen tended moved up to $548 \mathrm{~m}$ along an axis approaching the $\mathrm{N}-\mathrm{S}$ direction, and seeds were dispersed up to $990 \mathrm{~m}$, frequently along the SW and SE axes. Animal-mediated dispersal contributed significantly towards gene immigration into the local population and had a markedly nonrandom pattern within the local population. Our data suggest that animals can impose distinct spatial signatures in contemporary gene flow, with the potential to induce significant genetic structure at a local level.
\end{abstract}

Keywords: dispersal direction, dispersal distance, gene immigration, microsatellites, pollination, seed dispersal

Received 17 March 2006; revision accepted 21 August 2006

\section{Introduction}

Pollination and seed dispersal are two critical stages in plant recruitment cycles, frequently involving the interaction with one or more animal species that provide dispersal services for pollen or seeds (Howe \& Westley 1988). Thus, the feeding and post-feeding movements of pollinators and animal frugivores influence the distance, direction, and magnitude of pollen and seed dispersal, which ultimately determine the spatial pattern of gene movement within and among plant populations (Nathan \& Muller-Landau 2000). Pollinators and frugivores can remove large amounts of pollen and fruits, a fraction of which may be deposited several hundreds of meters away from the source tree

Correspondence: Cristina García, Fax: +34 95 4621125; E-mail: crisgarcia@ebd.csic.es
(Howe 1986; Harder \& Barret 1996; Nason et al. 1998; Schnabel et al. 1998; Godoy \& Jordano 2001; Hardesty et al. 2006), thereby connecting fragmented populations and favouring the colonization of new patches (Cain et al. 2000; Tewksbury et al. 2002). In spite of having demographic and genetic consequences for plant populations, the relative contribution of contemporary pollen and seed dispersal to overall gene immigration is still poorly reported.

Ideally, we should be able to characterize both pollen and seed dispersal movements (the processes) in order to understand their role in shaping the adult spatial distribution and genetic structure in plant populations (the patterns) (Bossart \& Prowell 1998). Dispersal usually involves an array of different vectors (biotic and abiotic) that distribute pollen and seeds nonrandomly over all available target sites, either receptive flowers (pollination) or deposition 
sites in the landscape (seed dispersal). When animals are the dispersal vectors, the distribution of propagules is aggregated and heterogeneous due to selective feeding movements (Fragoso 1997; Nason et al. 1998; Wenny \& Levey 1998; Jordano \& Schupp 2000; Schupp et al. 2002; Russo \& Auspurger 2004). The source of the dispersed propagules is usually unknown due to the difficulty of tracking pollen and seed movement (Cain et al. 2000). However, this information is highly relevant since it would provide reliable estimates on dispersal distance and directionally required to assess the role of dispersal processes in shaping the recruitment patterns and genetic structure in plant populations. Moreover, the ability to identify pollen and seed sources enables the dissection of the relative contribution of both gene vectors to a local population, an issue that has so far only been addressed by indirect estimates (Ennos 1994). Both aspects of contemporary pollen and seed dispersal are required to fully understand the ecological outcomes for plant species of plant-animal interactions.

The combination of genetic markers yielding individual multilocus genotypes with the spatial locations of both adult trees and dispersed propagules (either seed or pollen) provides a spatially-explicit framework for the study of seed and pollen dispersal and their long-lasting consequences in plant populations (Sork et al. 1999; Jordano \& Godoy 2002). Assignment methods allow local pollen and seed dispersal events to be tracked in terms of distance and directionality, while also enabling the identification of pollen and seed immigrants - i.e. those propagules collected in the study area but produced in another population - thus inferring the relative contribution of seed and pollen to overall gene immigration. Here, we used highly variable molecular markers (simple sequence repeats; SSRs) to identify the source tree for a sample of dispersed seeds, by genotyping the woody seed endocarps (a tissue of maternal origin) and comparing them with all adult trees within the population (see also Ziegenhagen et al. 2003; Grivet et al. 2005; Jones et al. 2005). The percentage of immigrant seeds can thus be estimated as the percentage of seeds with no matching genotype within the population, when the sampling is exhaustive (see Godoy \& Jordano 2001 for details). Our general goal was to estimate seed immigration in our study population and combine this estimate with previous results for pollen dispersal (García et al. 2005) in order to dissect the potential contribution of pollen and seed dispersal to total gene immigration. Second, we described and compared the seed and pollen dispersal patterns within the population in terms of distance and directionality from the source plants. If dispersal patterns of pollen and seeds essentially capture the foraging patterns of pollinators and frugivores, we expected a strong nonrandom and spatially-aggregated pattern of dispersal (Jordano \& Schupp 2000; García-Castaño 2001).

\section{Materials and methods}

\section{Study species}

The study species is Prunus mahaleb (L.), a gynodioecious rosaceous tree. In any given population there are individuals with hermaphrodite flowers (functional hermaphrodites) and others with androsterile flowers (functional females; Jordano 1993). In the southern Iberian Peninsula flowers are produced between mid-May and mid-June at high elevations (over $1300 \mathrm{~m}$ ). Bees (Hymenoptera: Andrenidae, Apidae) and flies (Diptera: Calliphoridae, Syrphidae) are the main pollen vectors (Jordano 1993). Between late July and mid-August, fleshy fruits are produced and consumed by frugivorous birds, such as blackbirds (Turdus merula), mistle thrushes (Turdus viscivorus), blackcaps (Sylvia atricapilla), and black redstarts (Phoenichurus ochruros) (Jordano \& Schupp 2000). Jordano (1995) reported seed dispersal by lizards (Lacerta lepida) and Herrera (1989) and J. L. García-Castaño (personal communication) reported seeds being dispersed by red foxes (Vulpes vulpes), badgers (Meles meles) and stone martens (Martes foina). See Jordano \& Schupp (2000) and García et al. (2005) for additional details.

\section{Study site and sampling design}

The study population is located in Nava de las Correhuelas (Parque Natural de Sierra de Cazorla, Segura y las Villas, Jaén province, Spain, $37-59^{\prime} \mathrm{N}, 2-54^{\prime} \mathrm{W}$ ) at 1615 m elevation. Populations of $P$. mahaleb in this region are typically isolated and small $(<100$ trees). Vegetation is dominated by grasslands with scattered patches of deciduous vegetation, gravely soil or rock outcrops covered by shrubs or small isolated trees. The rocky slopes are dominated by open pine forest (Pinus nigra ssp. salzmannii). Our study population consists of a total of 104 hermaphrodite and 92 female trees distributed as shown in Fig. 1. The next nearest P. mahleb population is found at $1.5 \mathrm{~km}$, and eight more are found within $20 \mathrm{~km}$

We analysed two distinct seed samples, one for the study of pollen dispersal patterns (see García et al. 2005) and the other for seed dispersal. To study pollen dispersal, we used 200 fruits harvested when ripe, before the start of consumption by frugivores, from the canopy of 20 mother trees previously used to characterize the mating system of Prunus mahaleb (L.) (for details on sampling design see García et al. 2005). To study seed dispersal we collected all dispersed seeds $(N=914)$ from seed-traps located at 613 sampling points all over the study area, each consisting of two seed-traps randomly located within a microhabitat type (for further details see García-Castaño 2001). We genotyped a random subsample of the dispersed seeds collected in the seed traps $(N=549)$. As some amplifications 


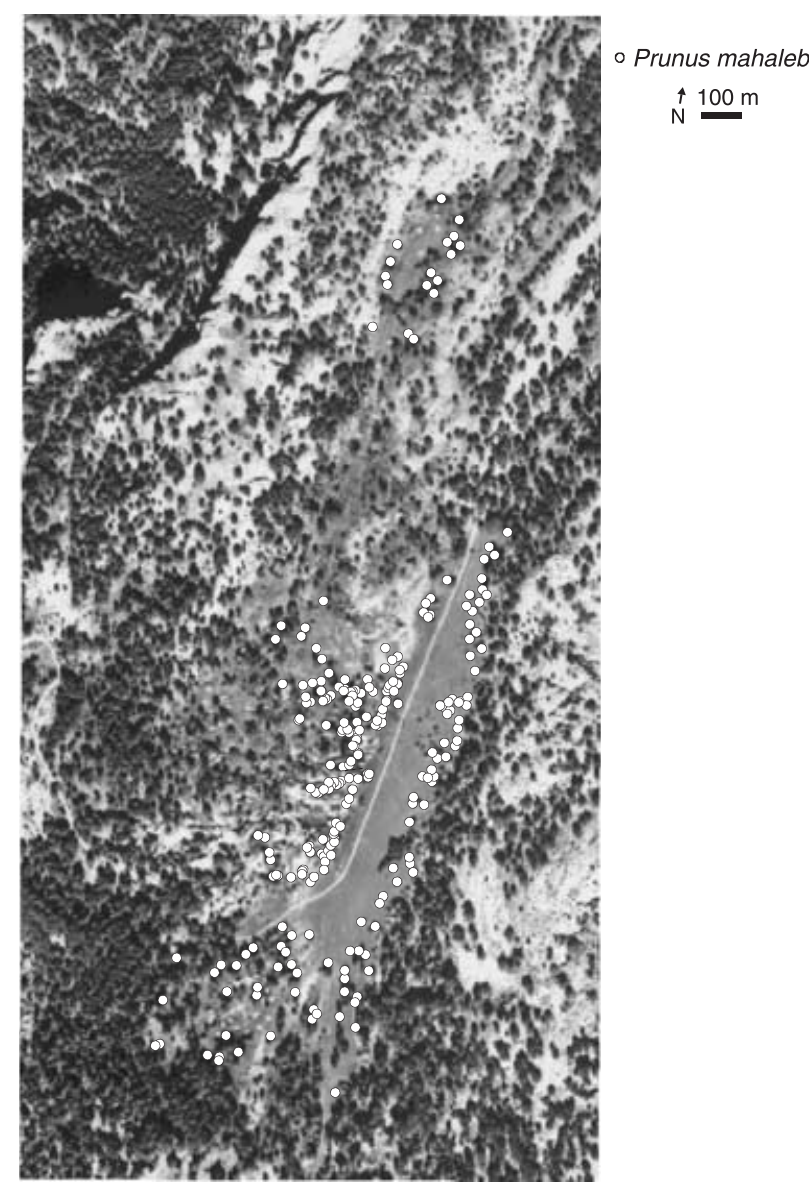

Fig. 1 Map of the study population showing the spatial location of all adult reproductive Prunus mahaleb trees (white dots). The area is highly heterogeneous, dominated by a pine forest (Pinus nigra ssp. salzmannii) at the edge of the P. mahaleb population, a central open grassland area, and rocky soils (white areas).

failed for several markers, we finally successfully obtained the multilocus genotype for at least eight markers for 465 endocarps.

\section{Microsatellite genotyping}

To obtain direct estimates of seed and pollen dispersal distances we obtained the genotype at 10 microsatellite loci for all adult trees within the population, along with the multilocus genotype of the endocarp of dispersed seeds and of the embryos extracted from the canopy-harvested seeds. The study population was previously genotyped and mapped by Godoy \& Jordano (2001), and a few trees were added to this previous sample by García et al. (2005). Briefly, endocarps were opened and separated from the embryo tissue and immersed in liquid nitrogen before being ground in a ball-mill (Retsch Mixer Mill MM 200). DNA was extracted following Cheung et al. (1993) and finally resupended in $80 \mu \mathrm{L}$ of TLE buffer (10 mM Tris- $\mathrm{HCl}$,
$0.1 \mathrm{~mm}$ EDTA). Five $\mu \mathrm{L}$ extract was used as template for the polymerase chain reaction (PCR). Amplified fragments were analysed using an ABI 310 Genetic Analyser (Applied Biosystems). The genotyping of adult trees was performed similarly, from leaf tissue. For further details on genotyping protocols see Godoy \& Jordano (2001). Embryos from fruits harvested directly from the mother tree were carefully separated from the endocarp and the seed coat. DNA was extracted from all embryos using a SIGMA GenElute ${ }^{\mathrm{TM}}$ Plant Genomics DNA Kit, with 5-10 $\mu \mathrm{L}$ used as a template for PCR in a final volume of $20 \mu \mathrm{L}$. Amplified fragments were analysed using an ABI 310 capillary electrophoresis system (Applied Biosystem). For full details on genotyping protocols for embryos see García et al. (2005).

\section{Data analysis}

Pollen immigration and paternity analysis. In a previous study we used paternity analysis to describe the mating system of this $P$. mahaleb population, by assigning a most-likely father to each pair of mother-offspring (paternity analysis) (for a detailed analysis of the procedure, see García et al. 2005). By doing so, we estimated the apparent pollen immigration as the percentage of embryos not assigned to a candidate tree within the population (Devlin \& Ellstrand 1990). We also used the set of unassigned (i.e. apparent gene flow) embryos along with the cryptic gene flow estimation to assess total (actual) pollen immigration. The cryptic pollen flow $(\mathrm{CPF})$ is defined as the fraction of the offspring assigned to a putative father within the population, whereas the true father is outside the population (Devlin \& Ellstrand 1990). We used CERVUs 2.0 for the paternity analysis (Marshall et al. 1998) following the criteria proposed by Slate et al. (2000) to define the scoring threshold, and FAMOz software (Gerber et al.2003) to estimate the pollen CGF. For the latter, we compared the estimate of actual pollen immigration provided in our previous paper (García et al. 2005) with the estimates for dispersed seeds. Additionally, we used the set of assigned embryos to characterize pollen dispersal patterns in terms of distance and directionality within the population.

Seed immigration and the assignment of the source tree for dispersed seeds. In order to identify the source tree for each dispersed seed (maternity analysis), we searched the matching genotypes between each endocarp and the candidate adult trees for a complete set of eight microsatellite markers out of 10 loci, as some loci were excluded due to a high frequency of failed amplifications. We used cERVUs 2.0 (Marshall et al. 1998) to identify the endocarp-source tree matching pairs, allowing zero mismatches. Given that all adult trees in the population yielded a different multilocus genotype, we assumed that endocarps with no matching adult genotype came from other populations, and we 
considered the percentage of nonassigned endocarps as an estimate of apparent seed immigration (Godoy \& Jordano 2001). We estimated the cryptic seed flow (CSF) that, in analogy to $\mathrm{CPF}$, represents the proportion of seeds assigned to a local source tree that have been produced outside the population. Based on Harju \& Nikkanen (1996) we estimated the sum of the all expected probabilities for the local maternal genotypes to be produced in a nearby population (i.e. the proportion of nondistinguible gametes; NDG). Assuming Mendelian inheritance, the HardyWeinberg equilibrium, and no linkage disequilibrium, this can be estimated based on the allele frequencies of the eight nearest populations (for details on the nearby populations see Jordano \& Godoy 2000). The actual seed flow is obtained by dividing the observed seed flow by NDG. Moreover, the simulations performed with CERvus indicated that with genotyping error rates ranging between 0 and 0.1 , an increment of 0.001 in the error rate increases the estimated seed immigration percentage in $2.5 \%$ (C. García, unpublished).

Intrapopulation dispersal distances and directions. The identification of the source tree for each pollen and seed dispersal event allowed the estimation of pollen and seed dispersal distances and directionality (Godoy \& Jordano 2001; García et al.2005). The $x, y$ coordinates for each adult tree and seed trap were recorded in a GIS database and used to calculate the distance and azimuth between each adult tree (i.e. intertree distance), each mother tree and their siring trees (i.e. pollen dispersal events), and between each dispersed seed and its source tree (i.e. seed dispersal events), with ARCVIEW 3.2 (Mitchell 1999). We tested for differences in pollen and seed dispersal distance distributions by applying a Kolmogorov-Smirnov nonparametric test. Additionally, we used ORIANA 2.0 (Kovach Computing Services, Wales, UK) to describe pollen and seed dispersal direction patterns. This software estimates the mean direction for both data sets. If we have $n$ observations and $\theta_{i}$ is the direction of the $n=i$ observation, we can calculate the mean vector direction as:

$\theta=\arctan (S / C)$

and the mean length as

$\bar{R}=\sqrt{S^{2}+C^{2} / n}$

where

$S=\sum_{i=1}^{n} \sin \theta_{i} \quad$ and $\quad C=\sum_{i=1}^{n} \cos \theta_{i}$

ORIANA 2.0 also provides statistical tests to assess if pollen and seed dispersal direction patterns differ from a uniform distribution (Rayleigh Z-test), and to compare pollen and seed dispersal direction distributions (Watson $U^{2}$-test for two samples). We expected the direction distributions to differ for pollen and seed dispersal since they result from the activity of different dispersal agents. To evaluate the influence of the adult hermaphrodite trees (pollen sources) arrangement in shaping pollen dispersal directions we estimated the potential pollen (PP) dispersal angle distribution in the population (angles between each sampled mother tree and each hermaphrodite in the population) and compared them with the actual pollen (AP) dispersal angle distribution (angle between each sampled mother tree and its siring hermaphrodite). Similarly, we compared the potential seed (PS) dispersal angle distribution (angle between each adult tree and each seed trap) and the actual seed (AS) dispersal angle distribution to evaluate the influence of the seed traps arrangement imposed by the sampling design on seed dispersal angle distribution. Both comparisons were performed by applying a Watson $U^{2}$-test for two samples (Zar 1999).

\section{Results}

\section{Among-population dispersal}

Observed seed immigration was more than twice the documented pollen immigration within the study site (García et al. 2005). While we found $20.34 \%$ of the dispersed seeds were derived from other populations, the previously reported percentage of actual pollen immigration showed that only $9.5 \%$ of the embryos were fathered by trees located outside the population. By relaxing the assumption of correct genotyping in allowing for one mismatch, we still obtained a high rate of seed immigration $(18.61 \%)$ - i.e. a conservative estimate between 19 and $20 \%$ of seed immigration. The proportion of nondistinguishable gametes was extremely low, NDG $=10^{-7}$, and therefore the actual seed gene flow should be almost equivalent to the above reported percentage of seed immigration. In terms of gene immigration, this means that 189 gametes carried by seeds (465 seeds $\times 2$ gametes $\times 0.2034)$ and 19.5 gametes carried by pollen (197 embryos $\times 1$ gametes $\times 0.0950$ ) came from other populations. Thus, 208.5 of the analysed gametes from a total of 1127 (seeds: $465 \times 2+$ pollen: $200 \times 1$ ) were immigrant, which represents $18.50 \%$ of the total gamete pool.

\section{Within-population dispersal}

Overall, pollen tended to move over shorter distances than seeds within the population, with a range of dispersal from $0 \mathrm{~m}$ (for self pollinations in hermaphroditic trees) to $548.0 \mathrm{~m}$. On the other hand, frugivore-mediated seed dispersal distances ranged from $0 \mathrm{~m}$ (seeds collected beneath the source tree) to $990.2 \mathrm{~m}$ (Fig. 2). The frequency distributions of seed and pollen within-population dispersal 


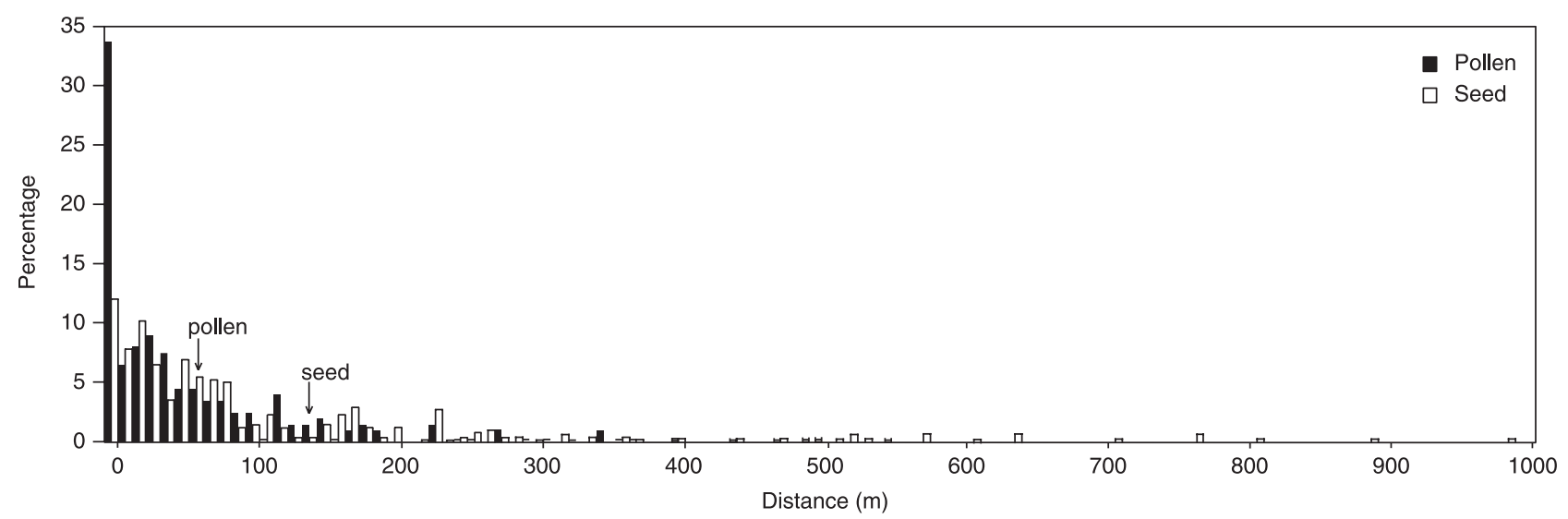

Fig. 2 Frequency distribution of the pollen (black bars) and seeds (white bars) dispersal distances in the study area. The high percentage of pollen dispersal events in the $0 \mathrm{~m}$ interval is due to selfing and the seed dispersal events in this interval mostly include seeds collected beneath the source tree canopy. The arrows indicate the median dispersal distance value.

distances differed significantly (Kolmogorov-Smirnov test, $\mathrm{Z}=5.71, P<0.01)$. The pollen dispersal distances had a median value of $62.9 \mathrm{~m}$, with $22.5 \mathrm{~m}$ and $129.3 \mathrm{~m}$ as the first and third quartile, respectively. The median seed dispersal distance was $145.2 \mathrm{~m}$, with $54.1 \mathrm{~m}$ and $267.3 \mathrm{~m}$ as first and third quartile, respectively (Fig. 2).

Potential and actual pollen dispersal angle distributions (PP and AP) did not differ $\left(U^{2}=0.155, \mathrm{df}_{1}=100, \mathrm{df}_{2}=2099\right.$, $P>0.05$ ) (Fig. 3a-b), while potential and actual seed dispersal angle distributions (PS and AS) differed significantly $\left(U^{2}=\right.$ 4.26, $\mathrm{df}_{1}=368, \mathrm{df}_{2}=120343, P<0.01$ ) (Fig. 3c-d). All circular histograms shown in Fig. 3 depicting the potential and actual angle distribution for pollen and seed differed from the uniform distribution $\left(U^{2}=11.46, P<0.01\right.$ for PP; $U^{2}=$ $0.50, P<0.01$ for AP; $U^{2}=190.25, P<0.01$ for PS; and $U^{2}=$ $0.43, P<0.01$ for AS). Actual pollen and seed dispersal directionality also differed $\left(U^{2}=0.595\right.$, d.f. $=362,100, P<$ 0.001 ), with an estimated mean vector $\theta=352.76^{\circ}$ and $R=$ 0.187 for pollen, and $\theta=174.30^{\circ}$ and $R=0.225$ for seeds (Fig. 3b, d). Thus, on average pollen moved with a marked $\mathrm{N}-\mathrm{S}$ directional component, but with wide variance from the NW and NE (Fig. 3b), whereas most of the dispersed seeds followed the SE-SW directions (Fig. 3d).

\section{Discussion}

Plant-animal mutualisms shape seed and pollen dispersal patterns in heterogeneous landscapes, having pervasive consequences on the genetic diversity, spatial distribution and recruitment patterns of plants (Nason et al. 1998; Schnabel et al. 1998; Hamilton 1999; Jordano \& Schupp 2000; Oddou-Muratorio et al. 2001; Westcott et al. 2005). Our results indicate that pollinators and frugivores generate extensive gene migration into the study population, despite its relative geographical isolation: $18.50 \%$ of the observed gametes came from another population. This level of gene immigra- tion might change quantitatively (amount) or qualitatively (population source) among years, but it is clear that a significant amount of gene migration connects our study population with nearby populations located between $1.5 \mathrm{~km}$ and up to $20 \mathrm{~km}$. The extensive gene flow observed is mainly due to a high percentage of seed immigration, which was double the pollen immigration in our population. This result is congruent with concurrent field work on the seed dispersal ecology of P. mahaleb in the same study population, showing that frugivores consistently remove a high fraction of the available fruit crop allowing for wide-ranging dispersal (Jordano 1995; Jordano \& Schupp 2000; GarcíaCastaño 2001). In contrast, other studies have reported pollen reaching longer distances than seeds, especially in outcrossed-anemophilous species with no special devices for seed dispersal, or with highly restricted seed dispersal around the mother tree by scatter-hoarding vertebrates (e.g. Quercus, Fagus, Pinus, etc.) (Ennos 1994; Nason et al. 1998). Recent evidence on vertebrate-dispersed species suggests that long-distance movements occur consistently and can account for a significant number of dispersal events, a pattern likely when large-bodied frugivores disperse the seeds (Fragoso 1997; Holbrook et al. 2002; Schupp et al. 2002; Bacles et al. 2004; Westcott et al. 2005). Pollinators are also able to fly long distances (Handel 1983) but, in the case of $P$. mahaleb, the patchy distribution of the adult trees coupled with their nonoverlapping phenology appears to restrict pollen immigration in the study population (García et al. 2005). The present study, along with recent publications dealing with fleshy-fruited species (Aldrich et al. 1998; Oddou-Muratorio et al. 2001; Bacles et al. 2004; Levey et al. 2005; Sezen et al. 2005), highlights the role that frugivorous vertebrates play in the interchange of individuals and genes among fragmented patches or populations.

As pointed out by Hamrick \& Nason (1996), the interpretation of spatial genetic patterns and their variation 


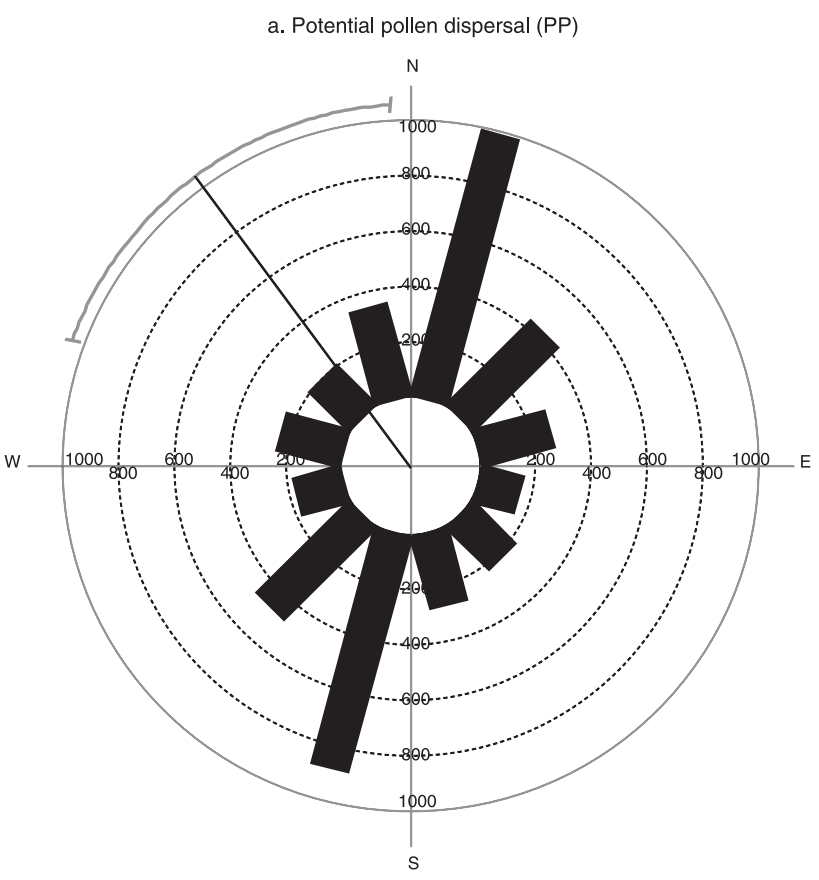

c. Potential seed dispersal (PS)

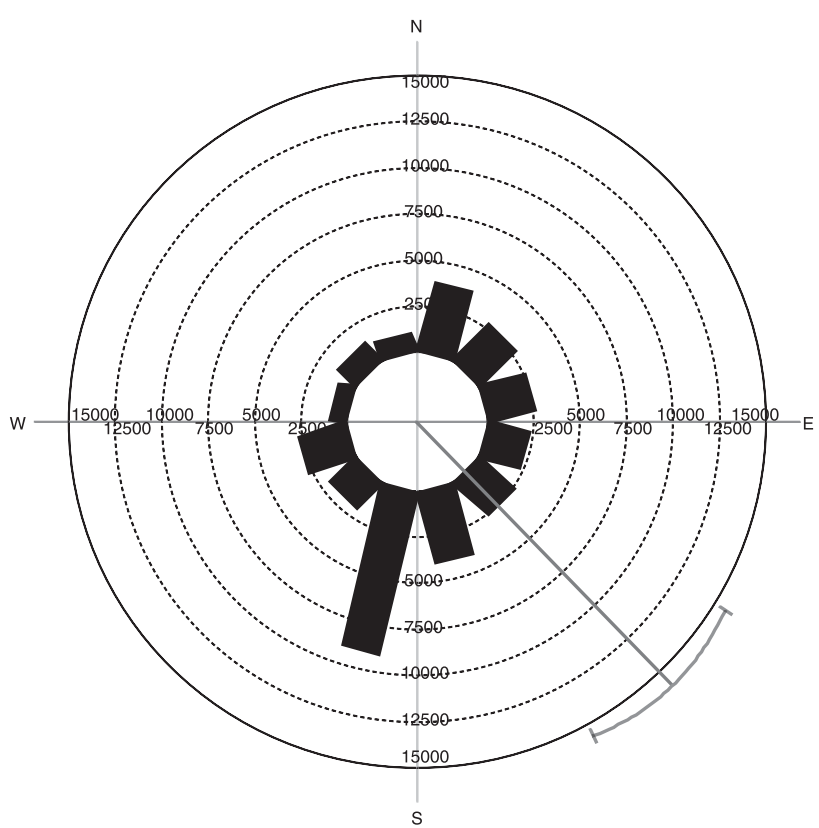

b. Actual pollen dispersal (AP)

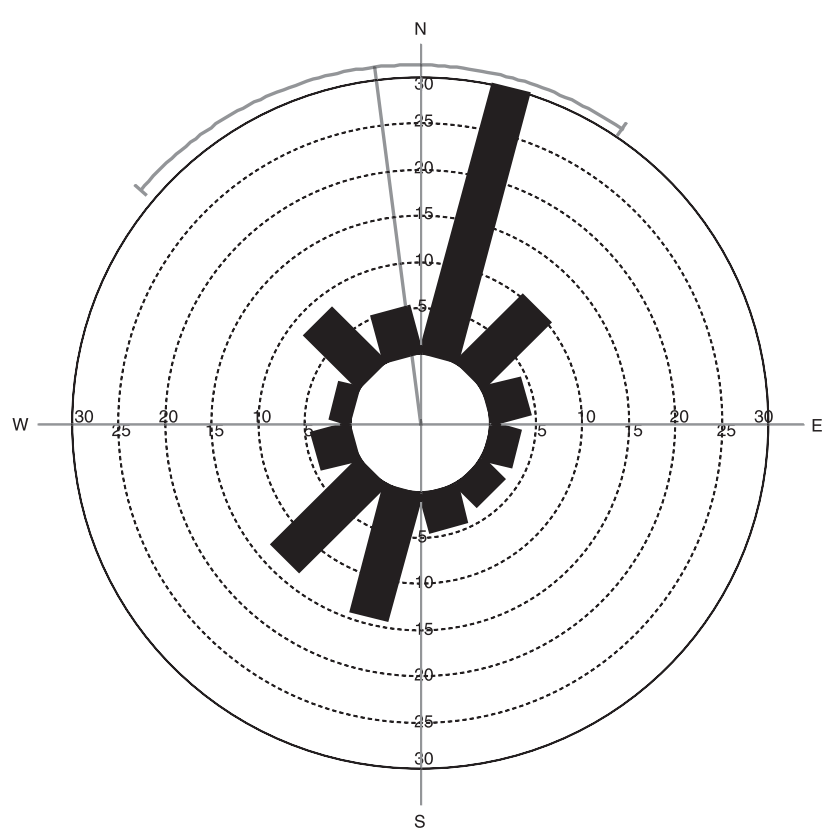

d. Actual seed dispersal (AS)

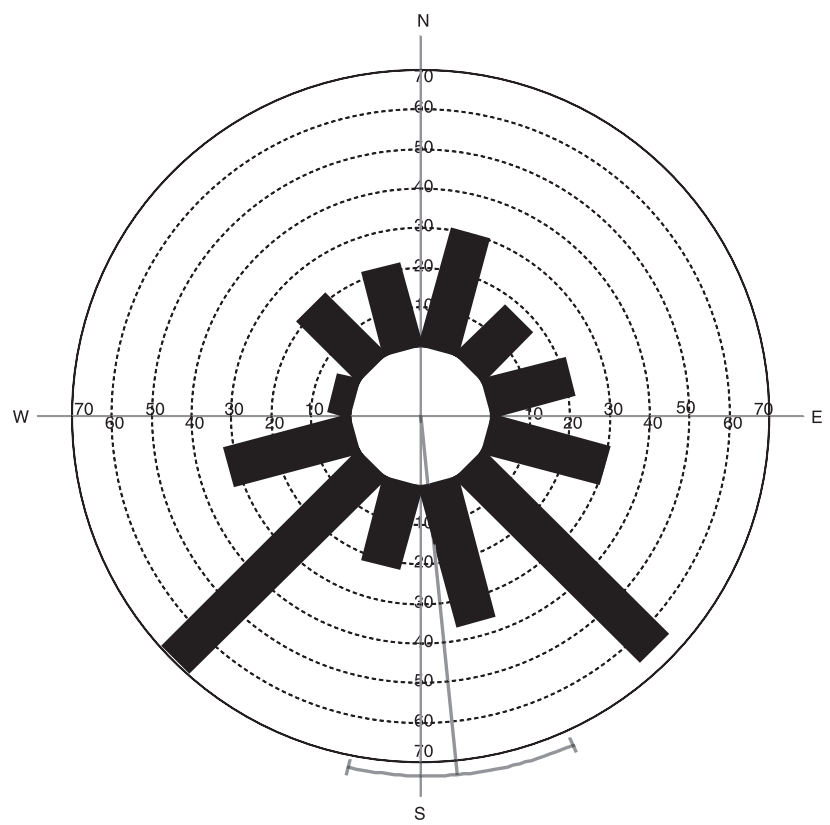

Fig. 3 Circular histograms of the directions distribution for the potential pollen dispersal events (a, PP), actual pollen dispersal events (b, AP), potential seed dispersal events (c, PS), and actual seed dispersal events (d, AS). The mean direction and the associated standard error are indicated as an inner solid line direction and an external bar and the figures on the axis are the sample size $(N)$. Note that the large difference on sample size between histograms containing potential dispersal events $(a, c)$ and actual dispersal events $(b, d)$ is due to the formers include all potential mother-father pairs and tree-seed trap pairs, respectively, whereas the latter include only the observed data.

requires the consideration of both pollen and seed dispersal biology. Despite the evidence for not-so-infrequent long-distance dispersal events (the tail of the dispersal curve), our data revealed highly skewed pollen and seed dispersal distance distributions, with almost $30 \%$ of the seeds and $47 \%$ of the pollen ( $23 \%$ excluding self-pollination events) being dispersed within a $30 \mathrm{~m}$ radius from the tree source. Additionally, a previous study reported frequent selfing in the same P. mahaleb population (García et al. 2005). These figures suggest that both seed and pollen dispersal 
are locally restricted, increasing in the long term the probability of the spatial clustering of related individuals (Heywood 1991), and therefore the emergence of spatial genetic structure at a fine scale. Moreover, by extending the study of dispersal from one dimension (distance) to two dimensions (directionality), our analysis shows that dispersal events are highly directional. This result suggests that the observed nonrandom and restricted pollen and seed dispersal patterns assisted by animals in heterogeneous landscapes set the initial conditions to generate a heterogeneous genetic spatial structure at a fine scale.

As in previous studies, we found a close relationship between disperser movements and the seed and pollen shadow patterns relative to the sources (e.g. Chase et al. 1996; Nason et al. 1998; Wenny \& Levey 1998; Jordano \& Schupp 2000; Jordano \& Godoy 2002; Schupp et al. 2002; Tewksbury et al. 2002). Pollen tended to move preferentially along a N-S direction following the spatial location of the adult trees, as confirmed by the lack of significant difference between the potential and actual pollen dispersal angles. Pollinators tended to fly from one P. mahaleb to the next one or to a nearby nonconspecific tree or shrub with an overlapping blooming, frequently located following the main N-S directional axis of tree arrangement. On the other hand, frugivores tended to forage, tracking the location of $P$. mahale $b$ trees and using short flights to nearby perches or, less frequently, longer flights to pine trees (Jordano \& Schupp 2000). These landscape effects on behaviour would explain that frugivores tend to frequently contribute dispersal events following the SE and SW directions. The dominance of the $\mathrm{S}$ vs. the $\mathrm{N}$ directions in the seed dispersal movements can also be caused by a higher frequency of open rocky patches and a lower availability of the more preferred, covered microhabitats in the Northern area of the population. Open substrates are rarely visited by frugivorous birds; only the black redstart (Phoenicurus ochruros) and mammals contribute to the scarce seed rain reaching open microhabitats (Jordano \& Schupp 2000; García-Castaño 2001). These results indicate that the combination of a complex landscape and the nonrandom behaviour of pollinators and frugivores can modulate distance effects by imposing directionalities and nonrandom paths relative to the flowering and fruiting trees (Herrera \& Jordan 1981). Therefore, our data suggest that animal vectors influence the template of propagules that starts the recruitment cycle, and that ultimately might shape the spatial demographic and genetic structure of the plant population.

Additional fieldwork involving long-term studies of marked individuals is required to assess the contribution of dispersal and postdispersal processes to recruitment patterns (Schupp \& Fuentes 1995; Aldrich et al. 1998; Kalisz et al. 2001). Direct data will elucidate the role of dispersal vectors due to their recurrent and nonrandom movements. However, we still lack a precise understanding of the differential survival prospects for immigrant progeny compared to in situ-dispersed propagules, and of the relative contribution of postdispersal mortality factors and local drift or selection modifying allele frequencies (Gram \& Sork 2001). The usefulness of the direct approach for dissecting pollen and seed dispersal contribution to overall gene flow and describing dispersal patterns is that it provides a first step towards the elucidation of the lasting consequences of plant-animal mutualisms in heterogeneous plant populations.

\section{Acknowledgements}

We are most grateful to J. M. Arroyo, whose valuable experience, patience, and generous and devoted work in the lab contributed to the success of this work. We are also in debt with J. L. GarcíaCastaño, J. G. P. Rodríguez and M. Carrión whose previous intensive field work made this study possible. P. Bazaga helped us in the lab and S. Martín with the GIS database. Pete Buston, Katrin B`hning-Gaese, Sophie Gerber, Andy Jones, Xavier Picó, Juanjo Robledo-Arnuncio, and Alfredo Valido greatly improved the early stages of the manuscript with their insightful comments and suggestions. Victoria Sork, Andrew Schnabel, Peter Smouse and four anonymous referees provided interesting comments and highly valuable suggestions. The Consejería de Medio Ambiente (Junta de Andalucía) greatly facilitated our work in Parque Natural de las Sierras de Cazorla, Segura y Las Villas. Our work was funded by grants BOS2000-1366-C02-01 and REN2003-00273 from the Spanish Ministerio de Ciencia y Tecnología (MCyT) and RNM-305 from the Junta de Andalucía; CG was funded by a MCyT research grant (FP2000-5627).

\section{References}

Aldrich PR, Hamrick JL, Chavarriaga P, Kochert G (1998) Microsatellite analysis of demographic genetic structure in fragmented populations of the tropical tree Symphonia globulifera. Molecular Ecology, 7, 933-944.

Bacles CFE, Lowe AJ, Ennos RA (2004) Genetic effects of chronic habitat fragmentation on tree species: the case of Sorbus aucuparia in a deforested Scottish landscape. Molecular Ecology, 13, 573584.

Bossart JL, Prowell DP (1998) Genetic estimates of population structure and gene flow: limitations, lessons, and new directions. Trends in Ecology and Evolution, 202-206.

Cain ML, Milligan BG, Strand AE (2000) Long distance seed dispersal in plant populations. American Journal of Botany, 87, 1217-1227.

Chase MR, Keseli R, Bawa K (1996) Distant gene flow in tropical trees. Nature, 383, 398-399.

Cheung WY, Hubert N, Landry BS (1993) A simple and rapid DNA microextraction method for plant, animal, and insect suitable for RAPD and PCR analyses. PCR Methods and Applications, 3, 69-70.

Devlin B, Ellstrand NC (1990) The development and application of a refined method for estimating gene flow from angiosperm paternity analysis. Evolution, 44, 248-259.

Ennos RA (1994) Estimating the relative rates of pollen and seed migration among plant populations. Heredity, 72, 250-259. 
Fragoso JMV (1997) Tapir-generated seed shadows: scale-dependent patchiness in the Amazon rain forest. Journal of Ecology, 85, 519529.

Garcìa C, Arroyo JM, Godoy JA, Jordano P (2005) Mating patterns, pollen dispersal, and the ecological maternal neighbourhood in a Prunus mahaleb (L.) population. Molecular Ecology, 14, 18211830.

García-Castaño JL (2001) Consecuencias Demogr.Ficas de la Dispersión de Semillas por Aves y Mamíferos Frugívoros en la Vegetación Mediterr.nea de Montaña. PhD Thesis, Universidad de Sevilla.

Gerber S, Chabrier P, Kremer A (2003) FAMoz: a software for parentage analysis using dominant, codominant and uniparentally inherited markers. Molecular Ecology Notes, 3, 479-481.

Godoy JA, Jordano P (2001) Seed dispersal by animals: exact identification of source trees with endocarp DNA microsatellites. Molecular Ecology, 10, 2275-2283.

Gram WK, Sork VL (2001) Association between environmental and genetic heterogeneity in forest tree populations. Ecology, 82, 2012-2021.

Grivet D, Smouse PE, Sork VL (2005) A novel approach to an old problem: tracking dispersed seeds. Molecular Ecology, 14, 35853595.

Hamilton MB (1999) Tropical tree gene flow and seed dispersal. Nature, 401, 129-130.

Hamrick JL, Nason JD (1996) Consequences of dispersal in plants. In: Population Dynamics in Ecological Space and Time (eds Rhodes OE, Chesser RK, Smith MH). Chicago University Press, Chicago.

Handel LD (1983) Pollination ecology, plant population structure, and gene flow. In: Pollination Biology (ed. Real L). Academic Press, New York.

Harder LD, Barret SCH (1996) Pollen dispersal and mating patterns in animal pollinated. In: Floral Biology: Studies on Floral Evolution and Animal Pollinated Plants (eds Lloyd AH, Barret SCH), pp. 140-190. Chapman \& Hall, New York.

Hardesty BD, Hubbell SP, Bermingham E (2006) Genetic evidence of frequent long-distance recruitment in a vertebrate-dispersed tree. Ecology Letters, 9, 516-525.

Harju AM, Nikkanen T (1996) Reproductive success of orchard and nonorchard pollens during different stages of pollen shedding in a Scots pine seed orchard. Canadian Journal of Forest Research-Revue Canadienne de Recherche Forestiëre, 26, 1096-1102.

Herrera CM (1989) Frugivory and seed dispersal by carnivorous mammals and associated fruit characteristics in undisturbed mediterranean habitats. Oikos, 55, 250-262.

Herrera CM, Jordano P (1981) Prunus mahaleb and birds: the high efficiency seed dispersal system of a temperate fruiting tree. Ecological Monographs, 51, 203-218.

Heywood JS (1991) Spatial analysis of genetic variation in plant populations. Annual Review of Ecology and Systematics, 22, 335355.

Holbrook KM, Smith TB, Hardesty BD (2002) Implications of long-distance movements of frugivorous rain forest hornbills. Ecography, 25, 745-749.

Howe HF (1986) Seed dispersal by fruit-eating birds and mammals. In: Seed Dispersal (ed. Murray DR), pp. 123-189. Academic Press, Sidney.

Howe HF, Westley LC (1988) Ecological Relationships of Plants and Animals. Oxford University Press, Oxford.

Jones FA, Chen J, Weng GJ, Hubbell SP (2005) A genetic evaluation of seed dispersal in the Neotropical tree, Jacaranda copaia (Bignoniaceae). American Naturalist, 166, 543-555.
Jordano P (1993) Pollination biology of Prunus mahaleb (L.): deferred consequences of gender variation for fecundity and seed size. Biological Journal of the Linnean Society, 50, 65-84.

Jordano P (1995) Frugivore-mediated selection of fruit and seed size: birds and St. Lucie's cherry, Prunus mahaleb. Ecology, 76, 2627-2639.

Jordano P, Godoy JA (2000) RAPD variation and population genetic structure in Prunus mataleb Rosaceae, an animal-dispersed tree. Molecular Ecology, 9, 1293-1305.

Jordano P, Godoy JA (2002) Frugivore-generated seed shadows: a landscape view of demographic and genetic effects. In: Seed Dispersal and Frugivory: Ecology, Evolution, and Conservation (eds Levey DJ, Silva WR, Galleti M), pp. 305-321. CABI Publishing, Wallingford, UK.

Jordano P, Schupp EW (2000) Seed disperser effectiveness: the quantity component and patterns of seed rain for Prunus mahaleb. Ecological Monographs, 70, 591-615.

Kalisz S, Nason JD, Hanzawa FM, Tonsor S (2001) Spatial population genetic structure in Trillium grandiflorum: the roles of dispersal, mating, history and selection. Evolution, 55, 1560-1568.

Levey DJ, Bolker BM, Tewsbury JJ, Sargent S, Haddad NM (2005) Effects of landscape corridors on seed dispersal by birds. Science, 309, 146-148.

Marshall TC, Slate J, Kruuk LEB, Pemberton JM (1998) Statistical confidence for likelihood-based paternity inference in natural populations. Molecular Ecology, 7, 639-655.

Mitchell A (1999) The ESRI Guide to GIS Analysis: Geographic Patterns and Relationships. ESRI Press, Redlands, California.

Nason JD, Allen EH, Hamrick JL (1998) The breeding structure of a tropical keystone plant resource. Nature, 391, 685-687.

Nathan R, Muller-Landau HC (2000) Spatial patterns of seed dispersal, their determinants and consequences for recruitment. Trends in Ecology and Evolution, 15, 278-285.

Oddou-Muratorio S, Pettit RJ, Le Gueroue B, Guesnet D, Demesure B (2001) Pollen versus seed-mediated gene flow in a scattered forest tree species. Evolution, 55, 1123-1135.

Russo SE, Augsplurger CK (2004) Aggregated seed dispersal by the spider monkey limits recruitment to clumped patterns in Virola calphylla. Ecology Letters, 7, 1058-1067.

Schnabel A, Nason JD, Hamrick JL (1998) Understanding the population genetic structure of Gleditsia triacanthos L.: seed dispersal and variation in female reproductive success. Molecular Ecology, 7, 819-832.

Schupp EW, Fuentes M (1995) Spatial patterns of seed dispersal and the unification of plant population ecology. Ecoscience, 2, 267-275.

Schupp EW, Milleron T, Russo SE (2002) Dissemination limitation and the origin and maintenance of species-rich tropical forest. In: Seed Dispersal and Frugivory (eds Levey DJ, Silva WR, Galetti M), pp. 19-23. CABI International, Wallingford, UK.

Sezen UU, Chazdon RL, Holsinger KE (2005) Genetic consequences of tropical second-growth forest regeneration. Science, 307, 891891.

Slate J, Marshall T, Pemberton J (2000) A retrospective assessment of the accuracy of the paternity inference program CERvus. Molecular Ecology, 9, 801-808.

Sork VL, Nason JD, Campell DR, Fern·ndez JF (1999) Landscape approaches to historical and contemporary gene flow in plants. Trends in Ecology and Evolution, 14, 219-224.

Tewksbury JJ, Levey DJ, Haddad NM et al. (2002) Corridors affect plants, animals, and their interactions in fragmented landscapes. 
Proceedings of the National Academy of Sciences of the United States of America, 99, 12923-12926.

Wenny DG, Levey DJ (1998) Directed seed dispersal by bellbirds in a tropical cloud forest. Proceedings of the National Academy of Sciences of the United States of America, 95, 62046207.

Westcott DA, Bentrupperbaumer J, Bradford MG, McKeown A (2005) Incorporating patterns of disperser behaviour into models of seed dispersal and its effects on estimated dispersal curves. Oecologia, 146, 57-67.

Zar JH (1999) Biostatistical Analysis. Prentice Hall, New Jersey.

Ziegenhagen B, Liepelt S, Kuhlenkamp V, Fladung M (2003) Molecular identification of individual oak and fir trees from maternal tissues of their fruits or seeds. Trees, 17, 345-350.
The authors belong to the Integrative Ecology Group (http:// ieg.ebd.csic.es) focused on the study of plant-animal interactions at Estación Biológica de Doñana (CSIC, Spain). Cristina García is a PhD student working on the spatial and genetic consequences of pollen and seed dispersal by animals in heterogeneous landscapes. Pedro Jordano studies the ecological factors that shape plant recruitment patterns, with a special interest on the theoretical, ecological, and evolutionary implications of plantanimal interactions. José A. Godoy is interested in the application of molecular markers to address ecological and evolutionary questions with a focus on endangered vertebrate species and conservation biology. 